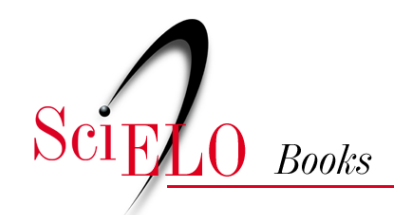

\title{
De povoado a município transformações socioeconômicas em Nilópolis
}

\author{
Enderson Alceu Alves Albuquerque
}

\section{SciELO Books / SciELO Livros / SciELO Libros}

ALBUQUERQUE, E.A.A. De povoado a município: transformações socioeconômicas em Nilópolis. In: MARAFON, G.J., and RIBEIRO, M.A. orgs. Revisitando o território fluminense, VI [online]. Rio de Janeiro: EDUERJ, 2017, pp. 189-208. ISBN: 978-85-7511-457-5.

https://doi.org/10.7476/9788575114575.0011.

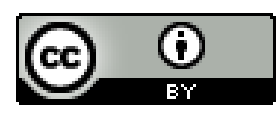

All the contents of this work, except where otherwise noted, is licensed under a Creative Commons Attribution 4.0 International license.

Todo o conteúdo deste trabalho, exceto quando houver ressalva, é publicado sob a licença Creative Commons Atribição $\underline{4.0}$.

Todo el contenido de esta obra, excepto donde se indique lo contrario, está bajo licencia de la licencia $\underline{\text { Creative Commons }}$ $\underline{\text { Reconocimento } 4.0 .}$. 


\title{
De povoado a município: transformações socioeconômicas em Nilópolis
}

\author{
Enderson Alceu Alves Albuquerque
}

\section{Introdução}

0

presente artigo apresenta o município de Nilópolis. As primeiras ocupações, populacionais e econômicas, seu processo de emancipação e as implicações de compor a segunda maior Região Metropolitana do país constituem seu cerne. Para tanto, procuramos abordar cronologicamente seu processo de ocupação territorial. Analisar esse espaço, desde as sesmarias até o presente momento, visa expor os sucessivos movimentos socioeconômicos pelos quais o município passou, bem como as consequências em seu território de tais processos.

Este artigo se divide em três partes. A primeira discorre a respeito das primeiras ocupações nos limites correspondentes a Nilópolis atualmente. Essa análise, embora não forneça subsídios para se compreender a atual configuração econômica do município, propõe um resgate cuja importância se deve aos limites territoriais de Nilópolis. Após sucessivos desmembramentos da sesmaria de Braz Cubas, João Álvares Pereira fundou a Fazenda São Matheus em 1634. Os limites dessa fazenda serviram de referência para a delimitação territorial de Nilópolis em 1947, ano de sua emancipação.

A segunda parte, consequentemente, analisa essa emancipação e os motivadores econômicos e demográficos implicados nesse processo, os agentes políticos envolvidos e as consequências iniciais dessa emancipação, além da dinâmica socioeconômica. Considerando a área oficial, Nilópolis, a partir da emancipação, passou a ser o oitavo menor município do país. Considerando apenas a área em que há ocupação de pessoas e atividades econômicas, Nilópolis seria o terceiro menor município do Brasil. Entretanto, quanto ao peso demográfico, nosso recorte espacial ocupa a posição de número

\footnotetext{
${ }^{1}$ Este artigo foi elaborado a partir de dissertação apresentada ao Programa de Pós-Graduação em Geografia da Universidade do Estado do Rio de Janeiro, sob a orientação do Prof. Dr. Miguel Angelo Ribeiro.

2 Mestre em Geografia pela Universidade do Estado do Rio de Janeiro.
} 
177 entre os 5.570 municípios brasileiros. Como essas especificidades influem na dinâmica socioeconômica do município?

Responder a tal questionamento é a intenção da terceira parte deste artigo, no qual buscamos contextualizar nosso recorte espacial na Baixada Fluminense e da RMRJ. Inicialmente, apresentamos uma revisão de literatura a respeito das diferentes concepções territoriais da Baixada Fluminense. A associação imediatista entre a Baixada Fluminense e os grupos de extermínio, os motivadores de seu processo de transformação e o quadro socioeconômico de Nilópolis nesse cenário serão contemplados nessa parte do artigo.

\section{De sesmaria a povoado de São Matheus: a gênese da ocupação territoria| ${ }^{3}$}

Entre os anos de 1530 e 1536, o governo de Portugal transplantou para o Brasil o sistema de capitanias hereditárias. $\mathrm{O}$ modelo de gestão territorial existia em seus domínios atlânticos, como na Ilha da Madeira (Boxer, 1992). As capitanias hereditárias consistiam em delegar à esfera privada a colonização do Brasil. Essa iniciativa da Coroa Portuguesa se devia às condições financeiras de seu reino à época, pois a restrição orçamentária inviabilizava a condução direta desse processo.

Assim, o território brasileiro foi dividido em 14 capitanias hereditárias. A extensão territorial correspondente ao atual município de Nilópolis integrava a Capitania Hereditária de São Vicente e tinha como proprietário Martin Afonso de Souza, em 1531. A ineficiência desse modelo, parcialmente explicado pela incapacidade técnica e humana de gestão dos enormes latifúndios doados aos nobres, a Coroa Portuguesa substituiu o sistema de capitanias hereditárias pelo de sesmarias.

Enquanto, no primeiro modelo, terras imensas foram doadas a pessoas abastadas como forma de protegê-las de conquistadores franceses e holandeses, as sesmarias se propunham a dinamizar a exploração econômica do território brasileiro, dando direito de posse à terra a quem comprovasse a efetiva possibilidade de cultivá-la (Alencastro, 2000). Por esse novo sistema, parte da Capitania Hereditária de São Vicente foi doada pela Coroa Portuguesa a Braz Cubas, em 1568. Essa sesmaria abarcava os limites territoriais que, hoje, compreendem os municípios de Nova Iguaçu, São João de Meriti, Duque de Caxias e Nilópolis (Oliveira, 2000). Nesse período, a região era ocupada por índios de diferentes etnias. Segundo Silva (2007, p. 69), esses índios poderiam ser os jacutingas. Para a autora, os primeiros registros de ocupação populacional da Baixada Fluminense diziam respeito a essa etnia: "As referências encontradas na maioria dos historiadores que escrevem sobre a ocupação dessa parte do território fluminense fazem alusão aos 'jacutingas' como o grupo que habitava essas terras, nomeados assim por conta de uma ave bastante comum naquela região".

\footnotetext{
3 Para esta parte do artigo, encontramos apoio em diferentes historiadores que utilizaram grafias distintas para fazer referência ao nome da fazenda e aos proprietários fundiários da cidade. Mantivemos a grafia de acordo com o autor considerado na citação.
} 


\section{De povoado a município: transformações socioeconômicas em Nilópolis}

A existência de inúmeras etnias nessa região e a inexatidão de sua extensão geográfica podem ter conduzido a análises reticentes por parte dos historiadores quanto às tribos locais. Silva (2007), na citação acima, utiliza expressões como "na maioria" e "alusão", termos descompromissados com a exatidão. Azevedo e Monteiro (2012, p. 51), por sua vez, referindo-se ao nosso recorte espacial específico, também apresentam precaução histórica: "A ocupação inicial das terras que hoje compõem a cidade de Nilópolis parece ter sido realizada pelos índios tupinambás, do grupo tamoio. A palavra tamoio significa, em tupi, os avós, ou os mais antigos, o que sugere a antiguidade desses índios como seus habitantes" (grifos nossos).

Pesquisas históricas estão sujeitas a imprecisões. Consequentemente, adotar diferentes fontes conduz a resultados distintos em relação ao mesmo fenômeno, os quais, contudo, não devem ser entendidos, necessariamente, como análises contraditórias. No caso da população indígena da área, por exemplo, os índios da etnia jacutinga poderiam ser os mais numerosos da região, conforme expõe Silva (2007), ao mesmo tempo que a atual área de Nilópolis era habitada pelos tupinambás, como ponderam Azevedo e Monteiro (2012). O certo é que eventuais divergências são comuns na prática de pesquisas históricas. Em nossa pesquisa para reconstruir o processo de ocupação do município de Nilópolis, outras divergências aparecem em relação a algumas datas.

De acordo com Nogueira (2008, p. 100), Braz Cubas não se apropriou das terras doadas pela Coroa Portuguesa. Entre a doação e os primeiros registros de atividade econômica nessa sesmaria, ficou um hiato: "Depois de desprezar as terras de sesmaria, de 03 de agosto de 1568 até a fundação da São Matheus, em 1634, 66 anos se passaram”. Para Oliveira (2008, p. 205), “em 1621 esta área denominada Fazenda São Mateus veio a pertencer a João Alvares Pereira”. Nogueira (2009, p. 39), por sua vez, esclarece que Pereira, "em 13 de junho de 1621, pediu e recebeu do governador Francisco Fajardo uma sesmaria de 1.500 braças de frente por 3 mil para o sertão, junto à serra do Tinguá. Em 1634, funda a Fazenda de São Matheus [...]”. Desse modo, para Nogueira, as terras recebidas por Pereira em 1621 não corresponderiam aos limites espaciais da Fazenda São Matheus, conforme assevera Oliveira.

A diferenciação de datas suscita discordância entre esses autores. Entretanto, ambos concordam quanto ao ano de construção da Capela São Matheus: 1637. Essa data é ratificada por Pizarro e Araújo (1820), o monsenhor Pizarro, em seu relatos de memória. De acordo com Peres (2010, p. 3), a capela foi construída "pelos índios existentes na região, já escravizados". Como exposto, não é possível definir qual tribo indígena foi responsável pela construção da supracitada capela. Entretanto, dois fatores relacionados à capela e à fazenda são inquestionáveis. $\mathrm{O}$ primeiro diz respeito à relevância produtiva da fazenda como primeira atividade econômica realizada naquele espaço; o segundo se relaciona com a importância simbólica da Capela São Matheus para a formação da identidade nilopolitana em um primeiro momento.

Nomear o povoado no qual estava instalada demonstra a crescente importância econômica da Fazenda São Matheus para a localidade. Os primeiros registros referentes à produção dessa fazenda datam de 1779. A Freguesia de São João Baptista de Trairaponga era composta por nove engenhos, dentre os quais o de São Matheus era o mais produtivo, com "uma produção anual de 30 caixas de açúcar e 14 pipas de aguardente, com 50 escravos negros” (Azevedo e Monteiro, 2012, p. 59).

No tocante aos aspectos simbólicos, a Fazenda São Matheus é de fundamental importância para a identidade do povo nilopolitano, sobretudo por ser o único fixo histórico localizado na par- 
te futuramente urbanizada de Nilópolis. Parte dos documentos históricos desse período se baseia em inspeções eclesiais. Nessa seara, são notórios os documentos atribuídos ao monsenhor Pizzaro. Os relatos aparecem em trabalhos destinados a analisar as primeiras ocupações na Baixada Fluminense, como, por exemplo, Simões (2008), Peres (2011) e Souza (2014). Apesar da pouca relevância desses relatos para o entendimento das forças produtivas, sua importância reside no fato de ressaltar como a Igreja Católica contribuiu para a formação identitária desses municípios da Baixada Fluminense.

Com o propósito de colonizar as terras da orla da Baía de Guanabara após a expulsão definitiva dos franceses protestantes, a Coroa portuguesa doou terras para a Igreja Católica, visando a ocupar a região em nome da "fé cristã e católica", assim como o era o reino português. Dessa forma, as funçôes realizadas pela instituição romana não se limitavam às de natureza religiosa, como casamento e batizados. A Igreja também registrava e validava óbitos e testamentos. Além disso, a partir da área de competência de determinada igreja, eram estabelecidos os limites territoriais civis. Segundo Torres (2004, p. 17), nesse período a Igreja Católica era de singular importância porque, "ao rezar uma missa no momento de posse da terra em 1500, o rei selava o compromisso de, onde quer que o seu poder estivesse, lá estaria a presença da Igreja, organizando, orientando, educando, fortalecendo, dando estrutura e até produzindo para o encantamento do reino".

Dessa forma, algumas localidades tiveram, inicialmente, seus nomes relacionados às primeiras igrejas que surgiram em seus domínios. Nesses casos, inserem-se Nossa Senhora do Pilar, Nossa Senhora de Belém e Menino Jesus, São João Baptista de Trairaponga, São Matheus, Nossa Senhora da Piedade de Magé, entre outras, conforme se observa no Quadro 1.

Quadro 1. Nomenclatura das toponímias selecionadas na Baixada Fluminense

\begin{tabular}{|l|c|c|c|}
\hline Anterior & Criação & Atual & Alteração \\
\hline Nossa Senhora do Pilar & 1612 & Duque de Caxias & 1943 \\
\hline São Matheus & 1637 & Nilópolis & 1921 \\
\hline $\begin{array}{l}\text { São João Baptista de Traira- } \\
\text { ponga }\end{array}$ & 1647 & São João de Meriti & 1660 \\
\hline $\begin{array}{l}\text { Nossa Senhora da Piedade } \\
\text { de Magé }\end{array}$ & 1696 & Magé & 1789 \\
\hline $\begin{array}{l}\text { Nossa Senhora de Belém e } \\
\text { Menino Deus }\end{array}$ & 1762 & Japeri & 1947 \\
\hline
\end{tabular}

Fonte: Prado (2000), Torres (2004), Simōes (2008) e Souza (2014).

Dos exemplos citados, apenas São João de Meriti manteve a toponímia associada à igreja católica. Antes chamada de São João Baptista de Trairaponga, a localidade manteve a homenagem ao santo com o acréscimo da palavra tupi Meriti. No caso de Magé, retirou-se do nome do município a referência religiosa, ficando apenas o termo tupi. Nossa Senhora do Pilar, primeira freguesia instalada na região, em 1612 (Prado, 2000), teve seu nome alterado para Duque de Caxias, em homenagem ao marechal de mesmo nome nascido naquela cidade. Japeri, nome de origem indígena, substituiu Belém. E São Matheus, atualmente, chama-se Nilópolis. 


\section{De povoado a município: transformações socioeconômicas em Nilópolis}

Em um primeiro momento, a identidade dos habitantes nilopolitanos era forjada a partir do pertencimento ao povoado de São Matheus. Entretanto, assim como nos demais exemplos baixadianos, o sentimento de identidade relacionado à primeira instituição católica local foi totalmente esvaziado. Do ponto de vista eclesial, para o historiador Marcus Antonio Monteiro Nogueira, isso ocorreu porque a capela era pequena e de propriedade particular. Em 1920, foi construída a Igreja de Nossa Senhora da Conceição, que passou ser a matriz da cidade, e a santa homenageada, padroeira de Nilópolis.

Do ponto de vista toponímico, a necessidade de atualizar homenagens de acordo com o progresso socioeconômico enfraqueceu as referências da fazenda. Se o esvaziamento toponímico de São Matheus ocorreu somente no início do século XX, o enfraquecimento econômico da fazenda ocorreu bem antes disso. Em 1854, a propriedade da fazenda passou para José Francisco de Mesquita, o barão do Bomfim. Posteriormente, ele passou o controle das terras a seu irmão, Jerônimo José de Mesquita, o barão de Mesquita (Peres, 2011, p. 3).

De acordo com Azevedo e Monteiro (2012, p. 70), a aquisição da fazenda por Mesquita objetivava "ampliar suas terras a serem atendidas pelos trilhos, pois o barão já era proprietário da Fazenda Cachoeira, cujas terras compõem o atual município de Mesquita e que fazia divisa com a São Matheus". A inauguração da estrada de ferro aconteceu somente em 1858, embora, seis anos antes, seu trajeto já fosse conhecido, por conta da divulgação de um edital público. Entretanto, antes da inauguração e somente após um ano da aquisição por Mesquita, a fazenda sofreu um primeiro revés, que, posteriormente, culminou com sua refuncionalização.

Em setembro de 1855, a cólera-morbo manisfesta-se na Freguesia de Meriti, especialmente nas fazendas de São Matheus e Cachoeira, ambas do Visconde de Bomfim, na época barão do Bomfim. Só na São Matheus, foram acometidos 51 escravos, dos quais 21 ficaram em estado grave e nove morreram. A epidemia persistiu até meados de novembro, fazendo mais vítimas. A fazenda recém-adquirida transformou-se num desastre (Nogueira, 2009, p. 64).

Essa epidemia assolou a maior parte da Baixada Fluminense. Trabalhadores livres e escravos, além de senhores de engenho, foram vitimados (Simões, 2008). A produção dos engenhos decresceu por causa da escassez de mão de obra e do esgotamento do solo. A diminuição do número de trabalhadores decorreu do surto epidemiológico, nessa conjuntura específica. Porém, a abolição da escravatura, em 1888, determinou o fim das atividades agrícolas na Fazenda São Matheus. Segundo Cardoso (1938, p. 26), essa fazenda, "que até então fora um campo de extensa e lucrativa produção, passara, a exemplo de muitas outras, a terrenos abandonados ao capricho da natureza, que a transformou em pouco tempo em um capoeirão e depois em mata fechada”.

A epidemia de 1855 e a abolição da escravatura em 1888, aliadas à inauguração da Estrada de Ferro Dom Pedro II (atual Central do Brasil), no ano de 1858, contribuíram para alterar a estrutura agrária da localidade. A impossibilidade de se manter esse modelo de reprodução do capital culminou com o desmembramento da Fazenda São Matheus a partir de 1896, inicialmente com a venda de dois terrenos (Nogueira, 2009).

Em 1900, a parte restante da Fazenda São Matheus, juntamente com suas edificações, foi vendida por Jerônimo José de Mesquita a João Alves Mirandela e seu sócio, Lázaro de Almeida 
(Peres, 2004). Os novos proprietários, então, foram os responsáveis pelo surgimento da cidade de Nilópolis. Em um primeiro momento, não houve alteração significativa na dinâmica social da localidade. João Alves Mirandela e seu irmão, Manuel Alves Mirandela, eram criadores de equinos. Pela natureza de sua atividade, os empecilhos que culminaram na crise da produção açucareira não representaram entrave para as atividades pecuaristas que os Mirandela pretendiam desenvolver. A utilização da área com essa finalidade, contudo, perdurou por apenas três anos, como relata Peres (2011, p. 3):

até 1913, parte da fazenda foi destinada à criação de muares e equinos para atenderem os clientes de Mirandela, até que, aceitando a sugestão do capitão Theodomiro Gonçalves Ferreira, foi levantada a planta da fazenda destinada ao seu loteamento. Dividida em lotes e divulgada sua venda nos jornais diários do Rio de Janeiro, sua procura foi um sucesso para as classes menos favorecidas, que adquiriam terreno barato ao preço de cinquenta mil réis, em módicas prestações mensais.

A divulgação da venda dos lotes foi feita por meio de anúncios pagos em jornais de grande circulação, como o Jornal do Commercio e o Jornal do Brasil. Em junho de 1914, "já haviam sido vendidos mais de 5.000 lotes e, já em princípio de 1915, estava totalmente vendida a área loteada ao lado direito da estação [...] apenas aguardando as construçōes" (Nilópolis, 2007, p. 12). Os preços dos lotes e a possibilidade de parcelamento do valor total favoreceram o êxito da venda, atraindo, sobretudo, as classes de menor poder aquisitivo. Ademais, alguns atrativos foram utilizados para mostrar o incipiente progresso da localidade a compradores em potencial. No material promocional de divulgação, por exemplo, os promotores destacavam a existência na cidade de bondes puxados a burro e já chamavam a localidade de Nilópolis (Azevedo e Monteiro, 2012).

Inicialmente em Nilópolis e, posteriormente, espraiado para outros municípios da Baixada Fluminense, o loteamento de terras se inscreve na estratégia do setor imobiliário para auferir maiores lucros. Para Pacheco (1984, p. 17),

este setor favoreceu o crescimento descontínuo do espaço metropolitano, na medida em que reservou terrenos mais próximos às áreas centrais como o intuito de esperar sua valorização, ao passo que áreas longínquas, além dos limites do então Distrito Federal, foram oferecidas à população de baixa renda, sem a necessária infra-estrutura urbana. É desse modo que desponta e se institucionaliza a periferia como habitat dessas populações pobres: atendendo aos interesses imobiliários.

Um dos representantes do setor imobiliário com atuação em Nilópolis foi Júlio de Abreu. "Homem de elevada importância na sociedade fluminense do início do século XX" (Oliveira, 2000, p. 27), Abreu inaugurou, no contexto nilopolitano, a prática de pressionar o Estado a promover melhorias que elevassem o preço de terras particulares. De acordo com Peres (2011, p. 3),

a falta de uma estação ferroviária no lugar da incômoda "parada" que atendesse a crescente população de São Mateus, evitando que os passageiros saltassem perigo- 


\section{De povoado a município: transformações socioeconômicas em Nilópolis}

samente sobre pedras e dormentes, fez com que seu proprietário se empenhasse junto à diretoria da ferrovia para a construção de uma plataforma com cobertura, evitando que as pessoas ficassem expostas às intempéries [...].

Se, por um lado, a construção da parada de trem atendia a uma demanda legítima da população, por outro servia aos anseios comerciais. Um dos artifícios dos proprietários fundiários consiste em valorizar seu patrimônio sem empregar capital próprio, beneficiando-se de recursos públicos. Corrêa (2004) ressalta, contudo, que tal benefício não se estende a todos os proprietários fundiários, contemplando apenas aqueles que mantêm estreita ligação com o poder público. A construção dessa parada de trem é emblemática quanto ao emprego dessa estratégia pelos proprietários fundiários. Dessa forma, em 8 de novembro de 1914, foi inaugurada a parada de trem Engenheiro Neiva, em homenagem ao engenheiro que a projetou, Lucas Soares Neiva. A localidade, antes chamada São Matheus, a partir do ano seguinte, de acordo com Oliveira (2000), passou a ser conhecida com o mesmo nome da parada de trem: Engenheiro Neiva.

Nesse contexto, Júlio de Abreu fundou o Bloco do Progresso em 1915. Formado por residentes influentes, essa agremiação trabalharia em prol do desenvolvimento local. Presidido por Abreu, o Bloco sugeriu que o lugar trocasse de nome. Seria retirada a homenagem feita a uma figura de importância meramente local, em prol de uma figura de relevância nacional: o ex-presidente da República, Nilo Peçanha. Enquanto, no campo simbólico, a troca apresentava um movimento inicial na tentativa da superar a condição de "aldeia" - batizar um espaço com o nome de um morador local não estava à altura do vertiginoso crescimento da localidade - no campo pragmático essa substituição funcionou como mais uma ação para alavancar a venda dos lotes. Então, com vistas a solidificar o nome, em 1918 o Bloco do Progresso lançou a revista Nilópolis.

Assim, paulatinamente, a localidade, embora ainda de maneira informal, passou a ser chamada de Nilópolis. O nome da parada de trem foi alterado em $1^{\circ}$ de janeiro de 1921 (Azevedo e Monteiro, 2012). A troca oficial do nome ocorreu em 6 de outubro do mesmo ano, pela Lei ${ }^{\circ} 1.705$, de autoria do deputado Manoel Reis. Essa lei registra, no art. 10: "Fica dada definitivamente a denominação 'Nilópolis' ao 70 districto do município de Iguassú [...]”.

De Fazenda São Matheus a Nilópolis, nosso recorte territorial passou por profundas alterações socioespaciais. $\mathrm{O}$ referido período presenciou a mudança de uma estrutura rural-agrária para outra de natureza urbano-comercial. Essa transformação foi fomentada, em um primeiro momento, pelos interesses dos proprietários fundiários, pois, conforme expõe Corrêa (2004, p. 16), eles

atuam no sentido de obter a maior renda fundiária de suas propriedades, interessando em que estas tenham o uso que seja o mais remunerador possível, especialmente uso comercial ou residencial de status. Estão particularmente interessados na conversão da terra rural em terra urbana, ou seja, têm o interesse na expansão do espaço da cidade na medida em que a terra urbana é mais valorizada que a rural. Isto significa que estão fundamentalmente interessados no valor de troca da terra, e não no seu valor de uso. 
Assim, a partir do loteamento, os proprietários fundiários converteram terras rurais em terras urbanas em uma proporção e uma velocidade sem precedentes no contexto local. Em um momento no qual a terra tinha pouco valor de troca, seu valor de uso foi potencializado. Daí em diante, o valor de troca se torna mais atraente que o valor de uso e as terras são fracionadas para loteamento.

O desenvolvimento alcançado por Nilópolis deu maior legitimidade a seu movimento de desvinculação do município de Nova Iguaçu. Sobre a atmosfera existente nesse período, é emblemático o que escreve Max Vasconcelos (apud Torres, 2004, p. 32): "É a Vincennes do Brasil, pela sua proximidade com a grande capital. O povoamento de ontem, mas seu progresso vertiginoso vaticina para breve a elevação desse districto à categoria de cidade". Nesse contexto, em 21 de agosto de 1947, Nilópolis se desvinculou do município iguaçuano. A análise desse processo, bem como de seus agentes e motivadores, é contemplada no próximo tópico.

\section{0 processo de emancipação nilopolitano: problemáticas da limitação territorial}

A inauguração da parada de trem em 1914 contribuiu, de forma, decisiva, para acelerar o processo de urbanização de Nilópolis e sua integração à malha urbana da cidade do Rio de Janeiro (Abreu, 2010). As áreas próximas à linha férrea tiveram imediata valorização, culminando, assim, com sua rápida comercialização. No entorno, surgiram as primeiras casas comerciais e a feira livre da cidade (Nogueira, 2009). A parada de trem gestou o centro comercial e financeiro da cidade. Entretanto, a urbanização nilopolitana não se deveu apenas a essa construção. A adoção de outras políticas públicas contribuiu, de forma significativa, para esse processo. Sobre os fatores que colaboraram para a intensificação dessa urbanização, Simões (2008, p. 84), aponta que

a simples passagem da ferrovia não garante a urbanização de um lugar; é necessário que se criem condições para que a população pobre se instale. A primeira condição é o surgimento do transporte de passageiros nos trens com uma certa regularidade e com preços de passagens mais acessíveis. A segunda condição é a possibilidade de acesso à propriedade da casa. Como as iniciativas de política habitacional popular na cidade do Rio de Janeiro, tais como vilas operárias, conjuntos habitacionais e mesmo a produção pequena burguesa, são insuficientes numericamente para atender à massa de trabalhadores pobres, é necessário criar uma alternativa que seja acessível a esta massa e não custe muito aos cofres públicos, já comprometidos com investimentos nas áreas mais abastadas e na infraestrutura voltada para a indústria. A alternativa será o loteamento popular.

As condições citadas por Simões fomentaram a urbanização de Nilópolis. O preço das passagens de trem foi padronizado. Pagava-se um só valor para viagens até a área central do Rio de Janeiro. Desse modo, essa política tarifária permitia que a população residisse em locais mais distantes de seu trabalho. Esse modelo de separação geográfica entre o local de trabalho e o de 


\section{De povoado a município: transformações socioeconômicas em Nilópolis}

moradia, possibilitado pela linha férrea, juntamente com os projetos de saneamento da Baixada Fluminense executados pelo então presidente da República, Nilo Peçanha, entre os anos de 1909 e 1910, foram os responsáveis iniciais pelo adensamento populacional de uma parte da Baixada Fluminense.

Até então calcadas no setor primário, essas alteraçôes estruturais ampliaram as possibilidades de se desenvolverem atividades econômicas no espaço nilopolitano. A conversão de terras rurais em urbanas gerou considerável crescimento demográfico. Surgiram, assim, novas demandas em Nilópolis. Tais demandas passaram a ser supridas com o surgimento e/ou expansão de novas atividades comerciais. A ampliação dessas atividades alimentou, consequentemente, o crescimento populacional. Nessa dinâmica de retroalimentação entre os processos demográficos e econômicos, o subdistrito iguaçuano alicerçou seu progresso.

Nilópolis compunha o primeiro subdistrito de São João de Meriti. Por sua vez, São João de Meriti era $4^{\circ}$ distrito de Nova Iguaçu. No ano de 1916, por indicação do deputado Manoel Reis, através da Lei no 1.332, Nilópolis passou a ser o sétimo distrito desse município (Azevedo e Monteiro, 2012). Essa mudança revelava a desenvoltura socioeconômica local. Em 1919, foi feito um novo loteamento no distrito. De acordo com Cardoso (1938, p. 12), nesse ano "o dr. Octavio Ribeiro de Faria Braga loteava suas terras do lado direito ferreo, edificando-se e povoando-se em marcha rápida [...]”. Em 1921, Rufino Gonçalves Ferreira loteou a parte remanescente do lado direito da linha férrea (idem, ibidem). Em 1932, a cidade passou a contar com uma linha de ônibus que a ligava ao bairro de Tomazinho (São João de Meriti). Quatro anos depois, Nilópolis ganhou sua primeira agência bancária, o Banco Lavoura (Oliveira, 2000). Em consonância com o dinamismo socioeconômico local, em 1938 foi realizado o último grande loteamento, surgindo, então, o bairro de Nova Cidade (Nogueira, 2008).

A partir de 1940, a questão da terra ganhou extrema relevância. Nesse período, "não havia mais terras disponíveis para loteamento na cidade, restando apenas a ocupação dos loteamentos já comercializados" (Simôes, 2008, p. 92). Nessa configuração fundiária, ocorreu a emancipação de Nilópolis. As bases do movimento foram se delineando naquela década. Em 1945, o deputado Lucas de Andrade Figueira solicitou, no ato das Disposições Constitucionais Transitórias, a criação dos municípios de Nilópolis e São João de Meriti (Torres, 2004). Em 21 de junho de 1946, ocorreu a solenidade de instalação do município de Nilópolis (Azevedo e Monteiro, 2012).

No dia 20 de junho de 1947, o município se desmembrou oficialmente de Nova Iguaçu. Em 15 de março, tomou posse João de Moraes Cardoso Junior, do partido UDN (União Democrática Nacional). Eleito com 2.269 votos, Cardoso entrou para a história municipal como primeiro prefeito eleito de Nilópolis (Torres, 2004). Tanto a emancipação política de Nilópolis quanto a de São João de Meriti - ambos municípios de Nova Iguaçu -foram efetivadas em 21 de agosto de 1947.

No tocante aos limites territoriais dos municípios nascentes, São João de Meriti contou com mais fatores positivos que seus vizinhos nilopolitanos. De acordo com Oliveira (2008, p. 206), ${ }^{4}$ a

\footnotetext{
${ }^{4}$ Há discordâncias quanto ao tamanho territorial de Nilópolis entre o IBGE, a prefeitura e alguns autores. Embora todos concordem com a delimitação de $9 \mathrm{~km}^{2}$ como a área urbanizada, o instituto
} 
Fazenda São Mateus serviria de referência para determinar os limites territoriais de Nilópolis, porém "cometeu-se nesta emancipação uma flagrante injustiça, pois, sendo a área de $22 \mathrm{~km}^{2}$, que era a mesma da Fazenda São Mateus, ficou reduzida a apenas $9 \mathrm{~km}^{2}$, perdendo 5,60 km² para o Gericinó; $5,60 \mathrm{~km}^{2}$ para São João de Meriti e $1,80 \mathrm{~km}^{2}$ para Nova Iguaçu”.

Enquanto para Oliveira (2000) a Fazenda São Matheus serviria como limite para engendrar a delimitação territorial do município de Nilópolis, Azevedo e Monteiro (2012, p. 57) apresentam novos limites territoriais históricos, ao acrescentarem que, "na região onde se situa a atual cidade de Nilópolis, se desenvolveram quatro grandes propriedades rurais, as fazendas São Matheus, Gericinó, Bananal e Cabral, sendo que apenas parte da área da antiga Fazenda São Matheus foi ocupada pela cidade". Para esses autores, os terrenos das antigas fazendas Cabral, Gericinó e Bananal, "apesar de pertencerem ao município de Nilópolis, nunca foram urbanizados”.

Segundo Azevedo e Monteiro (idem, ibidem), com exceção da São Matheus, todas as demais fazendas foram adquiridas ou apropriadas pelo governo federal. A área da Fazenda Gericinó foi comprada em 1908. A Fazenda Cabral, por sua vez, foi dividida e teve a primeira parte vendida para o governo federal em setembro de 1920. Os proprietários da parte remanescente rejeitaram a oferta do governo e tiveram suas terras desapropriadas em dezembro daquele mesmo ano. Já a Fazenda do Bananal foi adquirida pelo Exército em 1923. Dessa forma, os atuais limites territoriais do município de Nilópolis não correspondem fielmente à área da Fazenda São Matheus, pois parte dela foi incorporada ao município de São João de Meriti em 1947. Tampouco correspondem à soma das áreas das fazendas Gericinó, Bananal, Cabral e São Matheus, pois as três primeiras, embora componham oficialmente o território de Nilópolis, foram adquiridas e apropriadas pelo Exército antes do processo de emancipação de Nilópolis, em 1947. Assim, no processo de emancipação, Nilópolis ficou reduzido a apenas $9 \mathrm{~km}^{2}$ de área urbanizada; os outros $13 \mathrm{~km}^{2}$ compóem o Campo de Instrução Militar do Gericinó, conforme se vê na Figura 1.

federal considera 19,157 $\mathrm{km}^{2}$ a extensão total do município, ao passo que, para os demais, essa extensão seria de $22 \mathrm{~km}^{2}$. 


\section{De povoado a município: transformações socioeconômicas em Nilópolis}

Figura 1. Limites territoriais de Nilópolis: área urbana e Campo de Instrução Militar

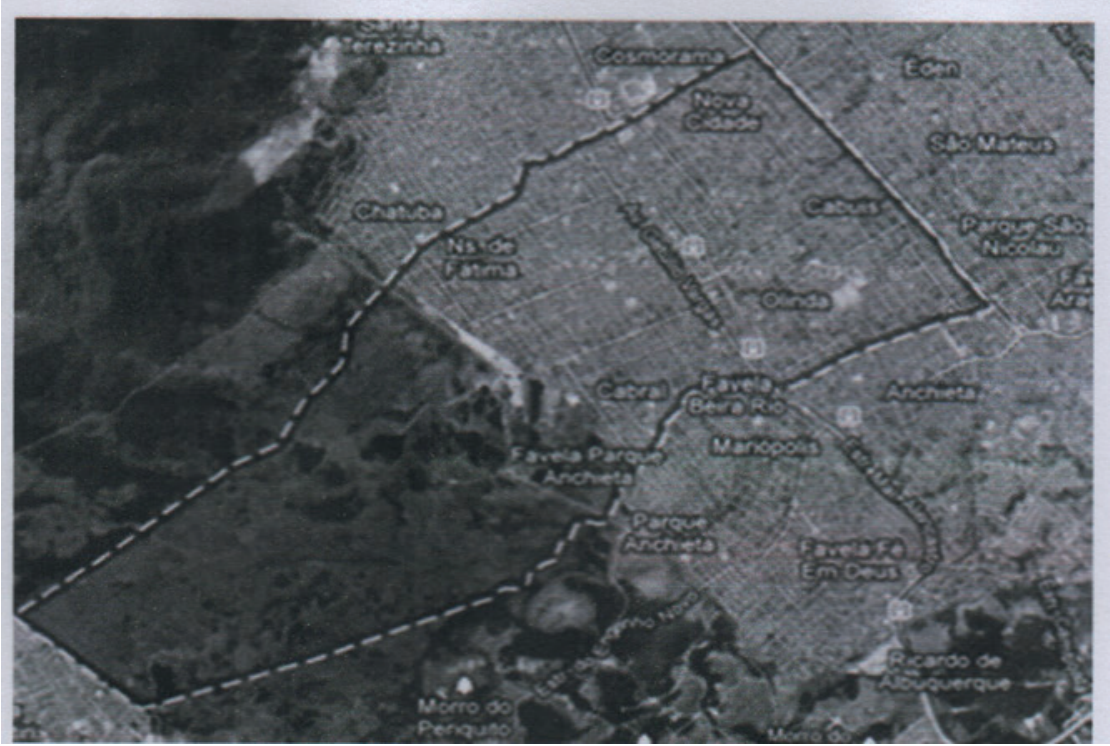

Fonte: Google Earth, 2012.

Desde a emancipação de Nilópolis, os sucessivos prefeitos da cidade reivindicam a municipalização da área ao governo federal. A incorporação dessa área aos limites territoriais de Nilópolis, de acordo o plano diretor da cidade, em seu artigo 14, inciso III, possibilitaria:

a. a melhoria da conexão de Nilópolis e da Baixada Fluminense com a Zona Oeste do Rio de Janeiro, notadamente Bangu e Campo Grande;

b. a consolidação do dique de contenção através de um parque ambiental e de lazer em seu entorno;

c. as funções administrativas e logísticas do Exército Brasileiro, caso queira e precise, sendo estas funções compatíveis e conviventes com um entorno residencial;

d. a previsão para desenvolvimento e fixação de atividades econômicas que necessitam de mais espaço físico, como indústria e logística, preferencialmente aqueles que tragam emprego e renda ao povo nilopolitano;

e. o espaço para habitação de qualidade ambiental urbanística e arquitetônica para todas as classes sociais e especialmente para os militares, populaçôes hoje moradoras da beira-rio e camadas médias e altas num conceito de cidade parque;

f. as vias marginais dos rios Sarapuí e Meriti/Pavuna, ampliando a ligação da Baixada Fluminense à Zona Oeste do Rio de Janeiro, e a própria inserção rápida e dinâmica da área de Desenvolvimento Estratégico de Gericinó às demais áreas das cidades de Nilópolis, Mesquita e Rio de Janeiro. 
Desde 2004, representantes do Exército e da prefeitura de Nilópolis estudavam, em conjunto, a proposta de transformar parte do campo de instrução em um parque de preservação ambiental. Porém, somente em 2009, foi criado o Parque Natural do Gericinó, com a proposta de "impedir o avanço de construções irregulares e propiciar a preservação, conservação e valorização da flora e da fauna do município" (Azevedo e Monteiro, 2012, p. 114). Além da preocupação ambiental, o parque é utilizado para a prática de atividades esportivas e de lazer.

Essa limitação territorial impôs ao município de Nilópolis entraves das mais diversas ordens, como, por exemplo, a impossibilidade de se criar uma área industrial. Também se verifica intensa pressão imobiliária, o que acarreta aumento do valor do solo e elevada densidade demográfica.

Os dados do Censo Demográfico do IBGE revelam que, no intervalo de trinta anos, houve um crescimento próximo de $472 \%$ da população residente em Nilópolis, passando de 22.341 habitantes em 1940 para 128.011 em 1970. Com essa configuração socioeconômica, nosso recorte espacial passou a compor, como unidade autônoma, a Baixada Fluminense em 1947 e a Região Metropolitana do Rio de Janeiro em 1973. As implicaçōes da inserçāo de Nilópolis nessas regiōes administrativas são no próximo tópico.

\section{Nilópolis no contexto da Baixada Fluminense e da Região Metropolitana do Rio de Janeiro}

Refletindo sobre as intervenções realizadas pelo governo de Nilo Peçanha entre os anos de 1909 e 1910, Lago (2000, p. 67) assinala que

essas obras de saneamento e drenagem executadas na Baixada Fluminense nesse período, em vez de impulsionar a produção agrícola para o abastecimento da cidade, abriram novas fronteiras para a expansão imobiliária. Surgia nesse momento um novo padrão de produção do espaço construído urbano, os chamados "loteamentos periféricos", que mudaria, doravante, a forma e o conteúdo não apenas do Rio de Janeiro, mas das demais grandes cidades brasileiras.

A alteração de forma e conteúdo aludida por Lago se manifestou pelo adensamento demográfico dos municípios vizinhos ao Rio de Janeiro. Em consequência, houve expansão da mancha urbana, até então limitada à cidade do Rio de Janeiro. No contexto fluminense, esse processo se materializou juridicamente com a criação da Região Metropolitana do Rio de Janeiro em 1973. Essa RM foi criada com 17 municípios, dentre eles o de Nilópolis, e teve como seu núcleo o então município da Guanabara (Figura 2). 
Figura 2. Localização do município de Nilópolis na RMRJ e na Baixada Fluminense

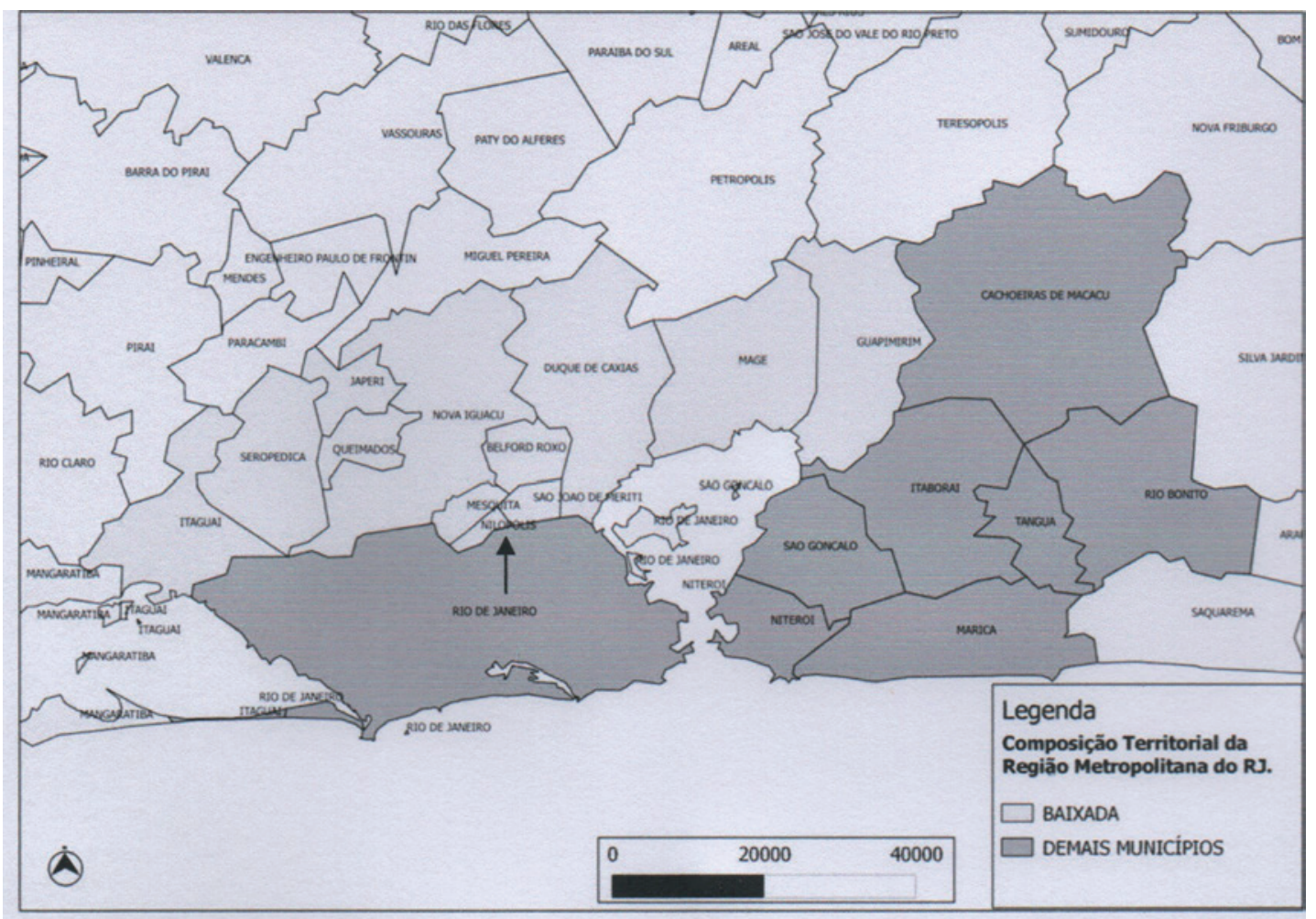

Fonte: Rocha, 2015 (modificado pelo autor).

A área metropolitana fluminense nasceu formada por dois estatutos jurídicos distintos, o do estado da Guanabara e o do estado do Rio de Janeiro. Havia um notório descompasso socioeconômico entre o núcleo da Região Metropolitana e seu entorno, como reforça Santos (2002, p. 13): “[...] separado administrativamente do seu entorno, o núcleo da região metropolitana não financiou a implantação da infraestrutura adequada para atrair investimentos industriais para a Baixada Fluminense".

A fusão do então estado da Guanabara com o estado do Rio de Janeiro, instituída pela Lei Complementar no 20, de $1^{\circ}$ de julho de 1974 , efetivada apenas no ano seguinte, 1975 , visava corrigir a separação entre o núcleo e a periferia da metrópole fluminense e de contribuir para o desenvolvimento da economia do interior fluminense por meio da consolidação de um polo de desenvolvimento obtido pela integração política e econômica dos dois estados. Também objetivava eliminar a barreira político-institucional entre a cidade do Rio de Janeiro e os demais municípios do estado do Rio (Davidovich, 2000).

O último Censo Demográfico do IBGE revela o caráter altamente concentrador do núcleo da RMRJ em comparação com os demais municípios. Essa área concentra $74,1 \%$ da população residente no estado, perfazendo um total populacional de 11.823.752 habitantes. Entretanto, 6.323.037 desses indivíduos residem no município do Rio de Janeiro. Dessa forma, o núcleo da RMRJ abriga, sozinho, 
população superior à soma dos outros 18 municípios que a compõem atualmente. Cumpre assinalar que, desde 2013, mais dois municípios foram incluídos nos limites metropolitanos: Rio Bonito e Cachoeiras de Macacu: "Uma das características fundamentais da região [metropolitana do Rio de Janeiro] é a concentração, tanto do ponto de vista demográfico quanto econômico, bem como o que diz respeito aos serviços referentes aos setores financeiro, comercial, educacional e de saúde, além de órgãos e instituições públicas" (Marafon et al., 2011, p. 94).

Nesse contexto, de uma área metropolitana altamente concentradora, Nilópolis se inscreveu como integrante de sua periferia ${ }^{5}$ (Ribeiro e O’Neill, 2012), a Baixada Fluminense. Essa região, por sua vez, não encontra consenso entre os pesquisadores no tocante a seus limites territoriais. Dependendo do critério adotado, o limite territorial e o número de municípios podem expandir-se ou retrair-se. No que diz respeito ao debate acadêmico, Oliveira (2004) nos apresenta três noçôes distintas das dimensões territoriais da Baixada Fluminense.

A primeira, pautada em critérios geomorfológicos, foi elaborada entre as décadas de 1930 (Góes, 1934) e 1960 (Geiger e Santos, 1955). No entanto, enquanto Góes se atém às características hidrográficas para estabelecer sua delimitação, Geiger e Santos consideram a "relação existente entre a sociedade e o espaço natural, dando ênfase às relações econômicas que predominavam em determinadas localidades” (Magalhães et al., 2013, p. 13), para erigir sua delimitação.

O certo é que a concepção de Baixada Fluminense extrapola a acepção meramente geomorfológica. Nesse sentido, conforme defende Oliveira (2004, p. 24), "o aspecto natural passou a ser associado com os elementos políticos, sociais e econômicos, apresentando construções distintas das verificadas acima”. Afinada com as proposições de Oliveira (2004), a segunda noção, engendrada por Beloch (1986), considera apenas os municípios que mantêm ligaçôes estreitas com o município do Rio de Janeiro - casos de Nova Iguaçu, Duque de Caxias, Nilópolis e São João de Meriti - como pertencentes à Baixada Fluminense.

A terceira conceituação, estabelecida pela Secretaria de Desenvolvimento da Baixada e Região Metropolitana (Sedebrem), considera que 13 municípios pertencem a essa região, como registra o mapa trazido na Figura 2. Essa delimitação territorial será a considerada para a estruturação deste estudo.

Assim, enquanto a primeira conceituação se atém às características naturais para delimitar a região, as demais recorrem a critérios socioeconômicos. Entre os trabalhos empreendidos para delimitar os limites físicos da Baixada Fluminense, merecem destaque ainda os de Segada Soares (1962) e Souza (2014). A primeira autora, por seu trabalho clássico sobre o processo de ocupação da Baixada Fluminense, e a segunda, pela revisão dos trabalhos referentes à região.

A caracterização da região, ao oscilar de acordo com os critérios adotados, como expõe, entre outros, Gomes (2010), abre a possibilidade de delimitaçôes distintas da Baixada Fluminense, tomando como referência os aspectos naturais ou os socioeconômicos. Nesse sentido, a delimitação de

\footnotetext{
5 Ribeiro (2002) subdivide o estado do Rio de Janeiro em dois espaços: a metrópole, constituída por seu núcleo e pela periferia (na qual está incluída a Baixada Fluminense), e o interior.
} 


\title{
De povoado a município: transformações socioeconômicas em Nilópolis
}

Baixada Fluminense apresenta limites nem sempre consensuais entre os pesquisadores que a tiveram como centro de suas reflexões. Simões $(2008$, p. 21) ressalta que

\begin{abstract}
não existe um consenso geral do que seja a Baixada Fluminense, quais os seus limites e os municípios que a compõem. A cada trabalho sobre essa região, reabre-se o debate, pois cada autor se coloca de maneira diferenciada com relação à área a ser delimitada. Contudo, existem alguns consensos que devem ser ressaltados. Os municípios de Nova Iguaçu e Duque de Caxias são apontados, com unanimidade, como núcleos desta região, assim como não há questionamento sobre a inclusão de seus "satélites" imediatos, como Belford Roxo, São João de Meriti, Nilópolis, Mesquita, Queimados e Japeri, que são incluídos como parte da Baixada Fluminense por todos os autores, mas nem sempre são analisados com a mesma profundidade que o "núcleo duro". Os problemas se encontram nos limites leste, oeste e norte. Dependendo dos autores, Magé e Guapimirim podem ser ou não inseridos na Baixada Fluminense, o mesmo ocorrendo com Itaguaí, Seropédica e Paracambi.
\end{abstract}

Independentemente da ausência de consenso no que diz respeito à delimitação territorial da região e de suas respectivas controvérsias, o recorte adotado foi associado à violência por muito tempo. Essa associação é fortemente consolidada no imaginário fluminense. Alves (2003, p. 15), por exemplo, relata o fato de uma deputada federal que, ao tomar conhecimento da chacina ocorrida no dia 30/08/1993 na favela de Vigário Geral, lamentou a tragédia "naquela favela da Baixada Fluminense". A parlamentar, em seu depoimento, associa a favela de Vigário (como é popularmente denominada) à Baixada Fluminense de forma equivocada. Essa declaração demonstra a associação direta estabelecida no imaginário entre violência e Baixada Fluminense. Tal associação começa a ser superada a partir dos anos 1990, quando a região dá início a um processo de transformação socioeconômica e político-partidária. Para Figueiredo (2004), essa condição passa a ser modificada porque,

em decorrência do período econômico favorável, houve investimentos públicos direcionados para a área, com a expansão do sistema de transporte na abertura de rodovias no final da década de 20 do século XX, como: Rodovia Washington Luiz, a antiga Rio-São Paulo, a Avenida Automóvel Club; a expansão da rede elétrica; a implantação do programa de saneamento da baixada (elaborado pelo governo de Getulio Vargas, em 1934), visando solucionar problemas que sempre a assolam, possibilitando o desenvolvimento dos transportes e a ocupação de terras; além da eletrificação da ferrovia ramal Central do Brasil-Japeri em 1938 até Nova Iguaçu, atingindo Japeri em 1943.

Desse modo, a região passa por uma alteração em virtude das transformações ocorridas em alguns de seus municípios. O dinamismo econômico verificado em Nova Iguaçu e Duque de Caxias - compreendido também segundo a lógica do espraiamento da metrópole do Rio de Janeiro - possibilitou o aumento da arrecadação municipal, favorecendo, assim, a infraestrutura local. Além disso, o fortalecimento econômico arrefeceu, em certa medida, as migraçóes pendulares entre a Baixada Fluminense e o núcleo metropolitano e entre os municípios dessa região. 
Quanto ao estereótipo de local violento, desde o início da década de 1990, a região passou a vivenciar o declínio dos grupos de extermínio e congêneres. A "espetacularização" da violência estendeu-se para o município do Rio de Janeiro, com ênfase para as favelas da Zona Norte e da Zona Oeste. Deslocaram-se, assim, os "holofotes" midiáticos de violência, até então centrados na Baixada Fluminense, para os bairros cariocas.

Com efeito, a Baixada Fluminense encontra-se em meio a um intenso processo de busca de identidade. Esse movimento propõe o rompimento com seu passado recente, que tanto contribui para a maneira caricatural como foi vista por tanto tempo. Contudo, enquanto a região passa a atrair novos fluxos financeiros, Nilópolis, na contramão desse processo, não presencia alteração significativa nessa área.

Ao compor uma área extremamente estereotipada como a Baixada Fluminense, Nilópolis também passa por um processo de transformação. Porém, sem a mesma força econômica dos municípios vizinhos, como Nova Iguaçu e Duque de Caxias, e sem a possibilidade de expansão urbana e industrial, por causa de sua pequena extensão territorial. Enquanto o município de Duque de Caxias absorvia 50,7\% da mão de obra local e Nova Iguaçu, mesmo englobando, a época, os municípios de Belford Roxo, Japeri e Queimados, retinha 44,7\%, Nilópolis absorvia, no mesmo período, apenas $35,2 \%$ da mão de obra local (IBGE, 2007).

Um dos elementos caracterizadores do baixo dinamismo econômico de Nilópolis na década de 1980 foi a incapacidade de suas atividades econômicas reterem a mão de obra local. Essa questão assumiu proporçôes drásticas com o aumento populacional, pois, em oitenta anos, segundo dados do Censo Demográfico do IBGE, houve um aumento superior a 3.000\% na população nilopolitana. Como o município tem uma extensão territorial pequena, sua densidade demográfica está próxima de 8.016 .6 hab. $/ \mathrm{km}^{2}$ - segunda maior densidade demográfica do estado, inferior apenas à de São João de Meriti.

Entretanto, a análise dos Censos Demográficos de 1991, 2000 e 2010 aponta para um período de decréscimo populacional em Nilópolis. Em 1991, 158.092 indivíduos residiam na municipalidade. Em 2000, esse número caiu para 153.712, voltando a subir para 157.483 em 2010. Contudo, a posição do município no total populacional do estado vem declinando. Em 1991, Nilópolis era o $14^{\circ}$ município mais populoso do estado. Em 2000, passou a ser o $16^{\circ}$ e, em 2010 , caiu para a $19^{a}$ posição. O esvaziamento demográfico de Nilópolis pode ser explicado, em parte, pelo surgimento de uma área próxima com melhor infraestrutura. Nesse caso, a chegada do metrô ao bairro carioca de Pavuna, mais próximo de São João de Meriti, teria tornado esse município mais atrativo do ponto de vista populacional, em detrimento do município nilopolitano.

Nesse mesmo período, os municípios limítrofes tiveram aumento de população. Porém, não é possível afirmar que o declínio populacional nilopolitano esteja alimentando os municípios vizinhos. Sabe-se, contudo, que foi a única cidade da Baixada Fluminense a perder população nesse período exceção feita a Nova Iguaçu, que apresentou uma perda populacional maior devido à emancipação dos municípios de Japeri (1991), Belford Roxo (1993) e Mesquita (1999).

$\mathrm{Na}$ esfera econômica, Nilópolis apresenta índices econômicos pífios em comparação a alguns municípios da Baixada Fluminense e da Região Metropolitana. Para o ano de 2012, o PIB total da Região Metropolitana, na qual Nilópolis está inserida, foi de R\$261.090.608 (em mil reais). O mu- 
nicípio nilopolitano contribui com apenas 0,74\% desse valor, com um PIB de R $\$$ 1.935.707. Nessa conjuntura, entre os 19 municípios integrantes da RMRJ, Nilópolis apresenta o 11\% PIB da região. Considerando os 13 municípios da Baixada Fluminense, nosso recorte espacial ocupa o sétimo lugar em relação ao PIB (TCE, 2014).

Internamente, a participação dos setores revela o destaque das atividades de serviços na composição econômica municipal, correspondendo a cerca de $90 \%$ do PIB do município (Tabela 1). Uma das explicaçōes para essa concentração pode ser formulada a partir da área urbana de Nilópolis, que inviabiliza a existência de atividades primárias e compromete o rendimento do setor secundário, pois, conforme assinala Corrêa (2004, p. 13), "os grandes proprietários industriais e das grandes empresas comerciais são, em razão da dimensão de suas atividades, grandes consumidores de espaço”.

Tabela 1. Participação das atividades na composição do PIB de Nilópolis (2007-2012)

\begin{tabular}{|l|l|l|l|l|l|}
\hline Ano & PIB (R\$ milhóes) & Agropecuária & Indústria & Serviços ${ }^{[1]}$ & $\begin{array}{l}\text { Administração } \\
\text { pública }\end{array}$ \\
\hline 2007 & 1.198 .642 & $0,0 \%$ & $10,28 \%$ & $89,72 \%$ & $36,51 \%$ \\
\hline 2008 & 1.374 .246 & $0,0 \%$ & $8,09 \%$ & $90,91 \%$ & $37,02 \%$ \\
\hline 2009 & 1.489 .045 & $0,0 \%$ & $10,41 \%$ & $89,59 \%$ & $36,92 \%$ \\
\hline 2010 & 1.685 .587 & $0,0 \%$ & $12,09 \%$ & $87,91 \%$ & $36,76 \%$ \\
\hline 2011 & 1.812 .902 & $0,0 \%$ & $11,81 \%$ & $88,19 \%$ & $37,17 \%$ \\
\hline 2012 & 1.935 .707 & $0,0 \%$ & $10,68 \%$ & $89,32 \%$ & $37,11 \%$ \\
\hline
\end{tabular}

[1] O setor de serviços compreende a administração pública.

Fonte: TCE (2012) e Ceperj (2013).

Como exposto na Tabela 1, Nilópolis apresenta características eminentemente urbanas. Segundo dados do IBGE, o município apresenta $100 \%$ da população residente nessa área. No contexto fluminense, embora a taxa de urbanização estadual seja de 96,6\%, dos 92 municípios, apenas outros dez apresentam taxa de urbanização na ordem de 100\%. Ribeiro e O’Neill (2015), apoiados em outros estudiosos, como Ester Limonad, José Eli Veiga e Angela Penalva Santos, questionam o critério adotado pelo IBGE para definir espaço urbano. Nesse sentido, Ribeiro e O’Neill (p. 9) construíram uma tipologia dos municípios fluminenses "utilizando três indicadores: da dimensão demográfica; do grau de urbanização; e do produto interno bruto (PIB)" para qualificar a questão urbana dos municípios.

Assim, de acordo com a metodologia adotada por esses autores e tomando como base o Censo Demográfico de 2010, Nilópolis, quanto à dimensão demográfica, é considerado um município de pequenas dimensóes (nesse grupo, estão aqueles com população inferior a 250 mil habitantes). Quanto ao nível de urbanização, nosso recorte espacial compõe o grupo dos municípios de grau muito forte (esse grupo compreende os municípios com urbanização acima de 80\%). Considerando a dimensão econômica, Nilópolis se enquadra na categoria fortemente de serviços (municípios em que o setor de serviços compreende mais de $80 \%$ do PIB). 
Para estabelecer a tipologia final, Ribeiro e O’Neill (2015, p. 10) procederam ao “cruzamento matricial da população total do município (dimensão demográfica); da relação entre população urbana e população total do município (grau de urbanização) e do PIB (dimensão econômica)". A partir desses indicadores, os autores dividiram o espaço fluminense em seis tipos. Nilópolis, a exemplo de outros cinquenta municípios, enquadra-se no tipo 1, que, segundo os autores (idem, ibidem), são municípios em que "há um predomínio do setor de serviços. Neste tipo, estão incluídos os municípios nas três classes de dimensão demográfica e com grau de urbanização superior a 45,0\%, predominando 35 com mais de $80,0 \%$ de urbanização [...]. São municípios que têm sua economia pautada no setor de serviços $[\ldots]$ ".

\section{Considerações finais}

Nilópolis passou por um profundo processo de alteração econômica estrutural. Até 1914, predominavam as atividades agrárias, alicerçadas, sobretudo, na produção de cana-de-açúcar. Atualmente, as atividades de serviços passaram a predominar na região. Essas alterações estiveram em consonância com a transformação de sua área de rural para urbano. A passagem da estrutura produtiva de rural-agrária para urbano-industrial gerou consideráveis implicações em nosso recorte.

O crescimento populacional exponencial verificado a partir dos loteamentos propiciou maior dinamismo econômico, e a soma dos incrementos econômico e demográfico culminou com a sua emancipação do município de Nova Iguaçu. Os termos segundo os quais essa emancipação foi efetivada respondem pela pequena extensão territorial do município, exatamente no período em que o processo de industrialização era o principal motor de desenvolvimento econômico no país. Nessa conjuntura, Nilópolis já nasceu excluída das possibilidades industriais. Nesse contexto e com o passar do tempo, suas discrepâncias econômicas aumentaram em relação a algumas cidades da Baixada Fluminense, tornando-a pouco participativa na composição do PIB total da RMRJ.

Dessa forma, a cidade não despontou como protagonista nesse novo cenário, em razão de sua pouca expressividade econômica. Em um primeiro momento, a cidade foi "sufocada" pelo desenvolvimento de municípios como Duque de Caxias e Nova Iguaçu, mais preparados, na ocasião, para receber os capitais antes preferenciais do município do Rio de Janeiro. Tomando como base os dados relacionados à porcentagem de população ocupada (Lago, 2010), podemos afirmar que o setor de trabalho melhorou em Nilópolis, fruto direto do incremento das atividades do comércio local.

Assim, o predomínio das atividades de comércio e serviços no espaço nilopolitano acompanha a tendência de aumento do setor terciário na composição da economia, tanto em escala nacional quanto em escala mundial. Essa alteração estrutural observada em Nilópolis, segundo Lago (2010), se explica pelo maior dinamismo econômico verificado nos centros periféricos da RMRJ. 
De povoado a município: transformações socioeconômicas em Nilópolis

\section{Referências}

ABREU, Maurício de Almeida. Evolução urbana do Rio de Janeiro. 4 ed. Rio de Janeiro: IPP, 2010.

ALECASTRO, Luiz Felipe de. O trato dos viventes: formação do Brasil no Atlântico Sul. São Paulo: Companhia das Letras, 2000.

ALVES, José Cláudio Souza. Dos barôes ao exterminio: uma história da violência na Baixada Fluminense. Duque da Caxias, RJ: APPH-CLIO, 2003.

AZEVEDO, Jorge Baptista de e MONTEIRO, Marcus. Inventário dos bens culturais de Nilópolis. Nilópolis (RJ): Prefeitura de Nilópolis, 2012.

BELOCH, Israel. Capa preta e Lurdinha: Tenório Cavalcanti e o povo da Baixada. Rio de Janeiro: Record, 1986.

BOXER, Charles R. O império maritimo português: 1415-1825. Lisboa: Edições 70, 1992.

CARDOSO, Ernesto. Nilópolis de hontem e de hoje. Nilópolis: L \& J. Berkowitz, 1938.

CORRÊA, Roberto Lobato. O espaço urbano. 4 ed. São Paulo: Ática, 2004.

DAVIDOVICH, Fany. "O estado do Rio de Janeiro: singularidades de um contexto territorial". Território, Rio de Janeiro, n. 9, 2000.

FIGUERÊDO, Maria Aparecida de. "Gênese e (re)produção do espaço brasileiro na Baixada Fluminense”. Revista Geo-Paisagem, Rio de Janeiro, ano 3, n. 5, 2004.

GEIGER, Pedro Pinchas e SANTOS, Ruth Lyra. "Notas sobre a evolução da ocupação humana da Baixada Fluminense". Revista Brasileira de Geografia, Rio de Janeiro, IBGE, ano XVI, n. 3, jul.-set. 1955.

GÓES, Hildebrando de Araújo. Relatório apresentado pelo engenheiro-chefe da Comissão de Saneamento da Baixada Fluminense. Rio de Janeiro: s. e., 1934.

GOMES, Paulo Cesar da Costa. "O conceito de região e sua discussão". In CASTRO, Iná Elias de et al. (orgs.). Geografia: conceitos e temas. Rio de Janeiro: Bertrand Brasil, 2010, pp. 49-73.

IBGE. Diretoria de Pesquisas, Coordenação de Contas Nacionais. Produto Interno Bruto dos Municípios 2007. Disponível em: www.ibge.gov.br.

LAGO, Luciana Corrêa do. Desigualdades e segregação na metrópole: o Rio de Janeiro em tempo de crise. Rio de Janeiro: Revan, 2000.

MAGALHÃES, Alex Lamonica et al. Alma(naque)... da Baixada. Rio de Janeiro: APPH-CLIO, 2013.

MARAFON, Glaucio José et al. Geografia do estado do Rio de Janeiro: da compreensão do passado aos desafios do presente. Rio de Janeiro: Gramma, 2011.

NILÓPOLIS. Revista de aniversário de 60 anos. Nilópolis: Prefeitura de Nilópolis, 2007.

NOGUEIRA, Marcus Antonio Monteiro. Baixada Fluminense: memórias fotográficas. Rio de Janeiro: Inepac, 2008.

- Memorial nilopolitano. Nilópolis: Prefeitura de Nilópolis, 2009.

OLIVEIRA, Cláudio de. Nilópolis: uma feliz cidade. Nilópolis: Fundação Padre Mateus, 2000.

—. "Evolução histórica dos distritos e os processos de emancipação: Nilópolis". In TORRES, Gênesis (org.). Baixada Fluminense: a construção de uma história: sociedade, economia, política. São João de Meriti: IPAHB, 2008. 
OLIVEIRA, Rafael da Silva (org.). Baixada Fluminense: novos estudos e desafios. [s.1.]: Paradigma Editora, 2004.

PACHECO, Susana Mara Miranda. Produção e reprodução de loteamentos na periferia do Rio de Janeiro (tese). UFRJ, 1984.

PERES, Guilherme. "O processo de urbanização: a Estrada de Ferro D. Pedro II”. In TORRES, Gênesis (org.). A contribuição de uma história. 1 ed. São João de Meriti-RJ: IPAHB, 2004.

—_. "Nilópolis, seu povo, sua história". Diário Fluminense, Nilópolis, nov. 2010-mar. 2011.

PIZARRO E ARAUJO, José de Souza Azevedo. Memórias históricas do Rio de Janeiro e das províncias annexas à jurisdiç̧ão do vice-rei do estado do Brasil. Rio de Janeiro: Impressão Regia, 1820-1822.

PRADO, Walter. História social da Baixada Fluminense: das sesmarias a foros de cidade. Rio de Janeiro: Ecomuseu, 2000.

RIBEIRO, Miguel Angelo e O’NEILL, Maria Mônica Vieira Caetano. “Considerações sobre a dinâmica populacional fluminense: contrastes entre a metrópole e o interior”. In MARAFON, G. J. e RIBEIRO, M. A. (orgs.). Revisitando o território fluminense IV. Rio de Janeiro: Gramma, 2012. . "Contrastes entre a metrópole e o interior fluminense a partir do urbano e do rural”. In FERNANDES, Ulisses et al. (orgs.). Velhos saberes, novas abordagens: a geografia à luz da contemporaneidade. Rio de Janeiro: Gramma, 2015.

ROCHA, André Santos da. "Os efeitos da reestruturação econômica metropolitana na Baixada Fluminense: apontamentos sobre o 'novo' mercado imobiliário da regiāo”. Revista Brasileira de Geografia Econômica, Rio de Janeiro, ano III, n. 6, jan.-jun. 2015, pp. 2-17.

SANTOS, Angela Moulin Simóes Penalva. Economia fluminense: superando a perda do dinamismo? S.1., 2002. Disponível em: www2.uerj.br/IPP.

SEGATAS SOARES, Maria Therezinha de. "Nova Iguaçu: absorção de uma célula urbana pelo grande Rio de Janeiro". Revista Brasileira de Geografia, Rio de Janeiro, ano 24, n. 2, abr.-jun. 1962, pp. 157-241.

SILVA, Maria Fatima de Souza. Das terras de Mutambó ao município de Mesquita-RJ: memórias da emancipação nas vozes da cidade. Mesquita/RJ: Entorno, 2007.

SIMŌES, Manoel Ricardo. A cidade estilhaçada: reestruturação econômica e emancipaçôes municipais na Baixada Fluminense. 1 ed. Mesquita-RJ: Entorno, 2008.

SOUZA, Marlucia Santos de. Escavando o passado da cidade: história política da cidade de Duque de Caxias. Duque de Caxias/RJ: APPH-CLIO, 2014.

TCE. Tribunal de Contas do Estado do Rio de Janeiro. Estudos socioeconômicos dos municípios: edições 2007 a 2012. Disponível em: http://www.tce.rj.gov.br. Acesso em: 21 out. 2015.

TORRES, Gênesis. "Baixada Fluminense: o processo de ocupação pela fé". In __ (org.). Baixada Fluminense: a construção de uma história: sociedade, economia, política. São João de Meriti: IPAHB, 2004. 